\title{
Occurrence and diagnosis of swine vesicular disease: past and present status
}

\author{
WIES ŁAW NIEDBALSKI, ANDRZEJ FITZNER
}

Department of Foot and Mouth Disease, National Veterinary Research Institute, Wodna 7, 98-220 Zduńska Wola, Poland

Niedbalski W., Fitzner A.

\section{Occurrence and diagnosis of swine vesicular disease: past and present status}

Summary

Swine vesicular disease (SVD) was first observed in Italy in 1966, where it was clinically recognised as foot-and-mouth disease (FMD). SVD virus (SVDV) was subsequently isolated in an FMD vaccine trial in Hong Kong. At the beginning of the 1970s, it spread to several other European and Asian countries: Bulgaria, Austria, Italy, Great Britain, Poland, former Soviet Union (Ukraine), Romania, France, Germany, Belgium, Switzerland, the Netherlands and Japan, and lasted until the beginning of the 1980s. After that period, SVD outbreaks were sporadic. The disease was almost forgotten until it flamed up again in 1992 in the Netherlands. Once again it spread to several other European countries, such as Belgium, Spain, Portugal and Italy. Since 1995, SVD has been reported in Europe almost exclusively in Italy, except two isolated outbreaks in Portugal. Since the last two SVD outbreaks in 2014 in the Potenza province (Basilicata region), no new SVD outbreaks have been reported either in Italy or in any other European country.

The clinical resemblance of SVD to FMD highlights the need for its reliable identification and discrimination. Differentiation from FMD, though not possible clinically, is feasible if appropriate diagnostic tests are applied. Improvements in diagnostic techniques are making differential diagnosis of vesicular disease increasingly affordable, feasible and easy, and nowadays, portable devices are capable of a rapid and accurate differentiation of SVDV from FMDV infections on site. As these tests become economical and as competent laboratory services become more and more accessible, the restrictions originally imposed on SVD because of its similarity to FMD will no longer be justified. This, together with the fact that in recent years SVD has been predominantly asymptomatic, makes it necessary to rethink the measures currently in place for the control and diagnosis of SVD. Therefore, by the decision of OIE, the SVD chapter was removed from the Terrestrial Code in January 2015. Consequently, the European Commission (EC) informed the Pirbright Institute that the EU Reference Laboratory for SVD would no longer receive financial support. Moreover, the EC position is that notification requirements have ceased in January 2015.

Keywords: SVD, occurrence, laboratory diagnosis

Swine vesicular disease (SVD) is an acute, highly contagious viral disease of domestic pigs and wild boars. As the clinical signs resemble those of foot-and-mouth disease (FMD), SVD was classified as an Office International des Epizooties (OIE) old list A disease until 2005. SVD does not cause severe production losses, but is of major economic importance, since control and eradication measures are costly, and countries which are known to have the disease face embargoes on the export of pigs and pig by-products. SVD is characterized by the appearance of vesicles around the coronary bands, on the skin of the metacarpus and metatarsus, and to a lesser extent on the snout, tongue and lips. Mortality, however, is rarely associated with SVD. It is spread by direct and indirect contact, as well as through infected feeds and contaminated environments. SVD is caused by the swine vesicular disease virus
(SVDV) of the genus Enterovirus within the family Picornaviridae (15), antigenically closely related to Coxsackie B5 virus, a human enterovirus $(33,34)$. It has been assumed that SVD may have arisen from the introduction of Coxsackie B5 into the pig population, but another mechanism for the antigenic similarity cannot be excluded, because sequence differences between Coxsackie B5 virus and SVDV are more extensive in the non-structural region compared to the structural part of the genome (33). Like other picornaviruses, the genome of SVDV is a single-stranded RNA with a positive polarity. This RNA consists of approximately 7400 nucleotides, which encode a single polyprotein of 2815 amino acids (10).

SVD was first recorded in October 1966, when vesicular disease appeared on two farms in Lombardy, Italy, and was originally termed "porcine enterovirus 
infection". On the basis of clinical signs of the disease in pigs, it was recognized as FMD, but the failure to confirm this diagnosis by laboratory tests led to a study that showed the causative agent to be an enterovirus (16). In 1971, SVDV was isolated in an FMD vaccine trial in Hong Kong (13) and outbreaks of SVD were also confirmed in Europe in Bulgaria (8). Since then, SVD has been reported in different European and Asian countries (Tab. 1). In October and December 1972, a number of SVD outbreaks occurred in Italy, in Campania, Lazio, Basilicata and Emilia-Romagna regions (8). Other outbreaks of SVD were confirmed in December 1972 in Austria in Wiener Neustadt and Talesbrus (12), and these outbreaks were associated with the importation of pigs from Poland, where SVDV was also isolated at that time $(12,29)$. Moreover, in 1972, the disease was reported in the United Kingdom, Romania (8) and the former Soviet Union (Ukraine, Odessa region) (14). Next year, the first outbreaks of SVD were recorded in Germany, France, Switzerland, Belgium and Japan (8, 13). Between 1975 and 1983, SVD occurred sporadically in France, the Netherlands, Malta and Belgium. In Germany and the United Kingdom, occasional SVD outbreaks were detected almost annually until 1982 despite the imposition of strict hygiene and control measures, but with the exception of Italy, the disease was eradicated from Europe by the early 1980s. Since 1992, however, there has been an increased number of cases of SVD in several clinical outbreaks in some countries of the European Union (EU) (Tab. 1). Nine outbreaks of SVD were confirmed in the Netherlands in 1992: in July, the disease occurred in breeding stock on three farms in the Gelderland province (Ede), and in October it was found on three more farms in the Netherlands, two of which were close to those involved in the July outbreaks (31). No new SVD outbreaks were detected until January 1994, when the disease reappeared in the Netherlands at a pig collecting centre at Haarle, Overijssel province. In 1992, SVD outbreaks were confirmed in Italy, in Modena and Siena provinces; both outbreaks involved animals belonging to the same consignment of pigs imported from the Netherlands (6). Moreover, in October 1992, during an SVD serological survey of pigs imported into Belgium from the Netherlands, sera containing antibodies to SVDV were found in fattening pigs originating from a farm in West Flanders Province. Then, in early February 1993, SVDV antibodies were detected in pigs on a farm in Antwerp Province, Belgium, where the virus was probably introduced by piglets imported from the Netherlands (6). However, in both cases no clinical disease was seen, and no SVDV could be isolated. During an SVD serological survey initiated in December 1992 in Spain, SVDV antibodies were detected in animals from 95 farms situated in different regions of this country. Furthermore, in February 1993, an outbreak of a vesicular condition in pigs was reported on a farm in Lerida Province in Catalonia, Spain, and in April 1993, SVDV was detected
Tab. 1. Swine vesicular disease outbreaks in the world, 19662014

\begin{tabular}{|c|c|c|}
\hline Country & Years of report & $\begin{array}{l}\text { Year of most recent } \\
\text { report }\end{array}$ \\
\hline \multicolumn{3}{|c|}{ Europe } \\
\hline Italy & $\begin{array}{c}1966,1972-1984 \\
1988-1989,1991-2014\end{array}$ & 2014 \\
\hline Austria & 1972-1976, 1978 & 1979 \\
\hline Bulgaria & 1971 & 1971 \\
\hline Poland & 1972 & 1972 \\
\hline United Kingdom & $1972-1977,1979-1981$ & 1982 \\
\hline Romania & $1972-1973$ & 1987 \\
\hline Ukraine & 1972 & 1975 \\
\hline France & $1973-1975,1982-1983$ & 1983 \\
\hline Germany & 1973-1977, 1979-1982 & 1985 \\
\hline Switzerland & 1973 & 1975 \\
\hline Belgium & 1973, 1979, 1992 & 1993 \\
\hline Netherlands & 1975, 1992 & 1994 \\
\hline Malta & 1975 & 1978 \\
\hline Greece & 1979 & 1979 \\
\hline Spain & 1993 & 1993 \\
\hline Portugal & 1995, 2003 & 2007 \\
\hline \multicolumn{3}{|c|}{ Asia } \\
\hline Hong Kong & $\begin{array}{l}\text { 1971-1977, 1979-1981, } \\
1984-1985,1987-1989\end{array}$ & 1991 \\
\hline Japan & 1973 & 1975 \\
\hline $\begin{array}{l}\text { The Republic of China } \\
\text { (Taiwan) }\end{array}$ & 1997-1998 & 2000 \\
\hline
\end{tabular}

at two farms in Huesca Province in north-eastern Spain (32). Two years later, in September 1995, the disease was recognized in western Portugal (11). An epidemiological investigation of SVD outbreaks from the 1970s and the next two decades by antigenic analysis of archival Polish SVDV isolates was performed in our laboratory with three panels of $\mathrm{mAbs}$ raised against Italian SVDV It 73, It 91 and It 92 in a trapping ELISA. It revealed that all SVDV isolates belonged to antigenic group 2 (viruses present in Europe and Japan between 1972-1981) (23). This suggests a close relationship between and a common origin of Polish isolates and the other European ones from the 1970s. The results of the antigenic analysis of SVDV isolates were confirmed by a phylogenetic analysis of the SVDV 1D coding region of archival Polish and other European and Japanese virus isolates from 1972-1981 (genogroup II) (21). These results showed their close genetic relationship and indicated that the distribution of isolates within these genogroups appeared to be related more to the year of their collection than to their geographical origin.

Since 1995, SVD has been reported in Europe almost exclusively in Italy, and elsewhere the disease was found on two isolated occasions in Portugal. In December 2003, an outbreak of SVD was reported on a farm in the 
Leira district, and then, in June 2007 , in the Beja district in that country (11) (Tab. 1). Until 1995, when the eradication plan was implemented in Italy, a vast majority of SVD cases had been recognized clinically: 4, 30 and 18 outbreaks in 1991, 1992 and 1993, respectively. Since then, almost exclusively the subclinical disease has been recognized. Fig. 1 presents the number of outbreaks in Italy over the period 1995-2014. From 1995 to 2001, the number of outbreaks varied from 5 to

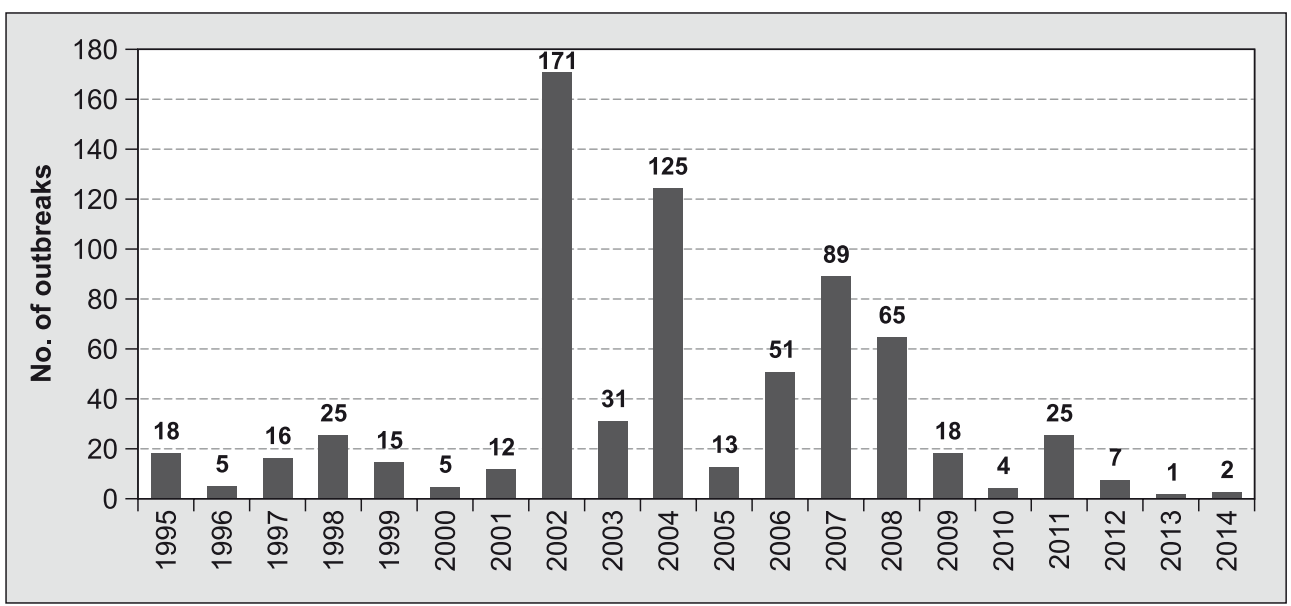

Fig. 1. SVD outbreaks in Italy, 1995-2014. Modified, according to http://ec/europa.eu
25 annually, but in 2002 as many as 171 SVD outbreaks were detected. The 2002 SVD epidemic originated in southern regions of Italy and progressively affected also central and northern regions (3). The maximum wave of SVD outbreaks was recorded during March and April 2002; then, the number of outbreaks slowly declined during the following months, and dropped steeply at the beginning of summer. One hundred and fifty outbreaks occurred in southern regions (Campania, Basilicata, Calabria) and in central Italy (Abruzzo, Molise, Lazio and Toscana); the most affected region was Calabria, with 102 outbreaks. These outbreaks were always eradicated following the adoption of rigorous control measures, and on some occasions extraordinary surveillance plans were implemented to verify the results of SVD eradication. The next great epizootic of SVD took place in Italy in 2004, when 125 outbreaks of the disease were reported. The most cases of SVD were recognized in central Italy (Abruzzo region), but the origin of infection remained unknown. In total, in the period 2003-2005, 169 outbreaks of the disease were reported in Italy: 18 in breeding farms, 40 on dealers' premises and 111 in fattening farms (Fig. 1). The results of the epidemiological investigations conducted during the years 2000-2005 in Italy confirmed that the spread of SVDV was related to the movement of animals (growers and sows), personnel and contaminated vehicles from the infected farms (3). In 2006-2007, SVD outbreaks occurred mostly in northern Italy (17). Lombardy, a densely populated pig area, was affected the most, and the presence of SVD caused heavy economic losses to the entire pig industry. On 2 October 2006, after SVD had been absent from the region for four years, 11 pigs tested seropositive at a slaughterhouse in the province of Bergamo which processed animals from various sources. Ultimately, in November 2006 a pig dealer in the Verona province was found to be the source of infection. By tracing pig movements from this farm, further outbreaks were identified in Veneto and Lombardy; in the latter region, the disease spread for more than one year (2). In February 2007, the outbreak seemed to have been controlled and eradication achieved. However, in
May 2007, after about three months without new outbreaks, the disease reappeared on a farm in Cremona, a province in the region of Lombardy that was not affected in the previous epidemic period (17). During 2006-2007, two epidemic waves were noted: first, from November 2006 to February 2007 in Lombardia (36 outbreaks), Veneto (8 outbreaks) and Emilia-Romagna (1 outbreak), and second, from July to October 2007 in Lombardia (17 outbreaks) (2). Genetic analysis revealed a "Portuguese" sub-linage of Italian SVDV isolates from 2007; the genetic similarity of these isolates to the POR 2003-2004 and 2007 was found (http://www. discontools.eu). In the following years, the number of SVD outbreaks in Italy decreased to 18 in 2009 (most in Calabria) and just 4 in 2010 in Campania, Latium and Sicily regions (http://ec.europa.eu). A sero-surveillance study performed in 2010 on 262240 pigs revealed 249 (0.1\%) SVDV seropositive animals. Out of 25 SVD outbreaks recorded in southern Italy in 2011, 24 occurred in Campania and 1 in Molise. In 2012, the number of outbreaks decreases to 7 (6 in Molise, 1 in Campania) and in 2013 to 1 (in Calabria); 2 outbreaks were noted in 2014 (in Basilicata). All SVD cases from 2012-2014 were confirmed exclusively serologically; all virological tests gave negative results, and no clinical signs were found. The seropositive animals were destined to slaughterhouse, and their meat was handled according to EU legislation (national market only, special mark). Since the last two SVD outbreaks (1 primary and 1 secondary) in April 2014 in the Potenza province (Basilicata region), no new SVD outbreaks have been reported either in Italy or in any other European country (http://ec.europa.eu).

SVD control measures were established in the EU by Council Directive 92/119/EEC, Annex II. This directive provides for a rigorous stamping-out policy, together with the establishment of protection and surveillance zones in which movements of pigs are restricted or banned, and cleansing and disinfection of infected premises and vehicles. Vaccination of pigs against SVD has never been undertaken in the field. However, considering the standards of animal welfare, a new 
strategy for controlling SVD is required, other than the stamping out policy. An improved understanding of the relationship between SVDV virulence, clinical expression and transmission may be useful in formulating an eradication programme in Europe and may lead to a rational design of effective marker vaccine candidates. If a vaccine can be developed that allows vaccinated pigs to be differentiated from those that have been naturally infected, policy options other than slaughter become possible. Member states have raised with the EU the issue of delisting the disease and removing obligations for disease control. New legislation may not be immediate and could be delayed until a review of the animal health law. However, the immediate impact of OIE delisting on EU law is not entirely clear (www. pirbright.ac.uk). Currently, Europe, Africa, America and Oceania remain free of SVD, but the disease is likely to be present in various parts of eastern Asia. The last officially reported case of SVD from Far East Asia was detected in the Republic of China (Taiwan) in 2000 (8). However, although the EU is currently free from SVD, the globalization and intensification of international trade in animals and animal by-products as well as the global tourism create the risk of re-emergence of the disease in Europe.

Rapid and accurate detection of SVDV is critical not only because the disease is highly contagious, but also because it facilitates the differentiation of SVD from the other vesicular virus diseases, namely: FMD, vesicular stomatitis (VS), vesicular exanthema of swine (VES) and the disease caused by Senecavirus A (SVA) (1). Diagnostic procedures for SVD are currently laid down at the Community level in Commission Decision 2000/428/EC. It establishes diagnostic procedures, sampling methods and criteria used in evaluating the results of laboratory tests for the confirmation and differential diagnosis of SVD. As it is impossible to differentiate SVD from the other vesicular diseases on the basis of clinical signs alone, SVD must be confirmed by detecting the virus or specific viral antibodies in biological samples. Specimens required for diagnosis include vesicular fluid, vesicular epithelium, whole blood and faecal samples from animals with and without lesions. Moreover, the use of swine oral fluid (OF) for the detection of SVDV and specific antibodies is gaining significant popularity (30). The virus neutralization test (VN) and the enzyme-linked immunosorbent assay (ELISA) are used for the examination of sera for SVDV antibodies (5). SVDV is routinely identified by its isolation in cell culture (in primary and secondary swine cell cultures and in the continuous cell lines IB-RS-2, SK-6 and PK-15), antigen ELISA and conventional gel-based reverse transcription-polymerase chain reaction (RT-PCR) or real time RT-PCR (rRT-PCR) (7, 26, 27). The SVDV genome can also be detected by the simple and rapid one-step reverse transcriptase loopmediated isothermal amplification assay (RT-LAMP) (4). The VN and the competitive ELISA assay based on a specific monoclonal antibody (MAC-ELISA) are routinely used in our laboratory for the serological diagnosis of the disease (25). These assays are specific and sensitive, but some animals (1-3 per 1000) still give false positive results in both tests. It is known as a singleton reactors (SR) phenomenon, which concerns samples originating from pigs that give positive results for the SVDV antibody but have no history of contact with the virus. The origins of SR still remain unknown. Detection of SR causes economic losses for the farm of origin and presents problems for international trade. To reduce non-specific positive results (SR) recorded in the VN and MAC-ELISA, we applied the isotypespecific trapping ELISA test (20). It was found that the sera from SRs were characterized by the presence of exclusively SVD-specific IgM, but not IgG, and the low-titre, cross-reactive IgM antibodies were the cause of the SR phenomenon. To detect SVDV in suspected material, the conventional diagnostic methods such as virus isolation (VI) and indirect-sandwich ELISA are routinely used in our laboratory. In 1995, we successfully applied RT-PCR for the detection of the SVDV genome in an infected cell culture (24). The period of SVDV persistence in clinical and tissue samples (nasal swabs, blood, faeces, epithelial tissue from vesicles) from experimentally infected pigs was investigated by conventional and nested PCR (RT-nPCR) assays (18). It was shown that this technique can be very useful in estimating the duration of infection in pigs with SVDV. Additionally, in 2009 we applied a primer set that targets the internal ribosomal entry site (IRES) region of the SVDV genome and the TaqMan probe specific for a highly conserved region in the SVDV IRES region to detect the viral genome by rRT-PCR (19). This assay detected viral RNA in all tested archival strains of SVDV isolated in Europe during 1972-1973 and in 1992, as well as in clinical samples collected from experimentally infected pigs. Recently, we have developed an RT-LAMP assay for the detection of SVDV RNA in biological samples. Three sets of specific primers targeting the conserved 3D polymerase genome and a novel fluorescent dye isothermal mastermix containing GspSSD polymerase were used. Our preliminary results proved it to be a sensitive, specific and rapid assay for the detection of the SVDV genome (unpublished data). Most of the SVD laboratory diagnostic methods presented above require a dedicated laboratory facility, highly trained personnel and stable reagents, as well as multistep sample handling or preparation. Such special conditions are not required for the recently developed lateral flow device (LFD) method for the detection of SVDV in clinical samples, which can be used in the field (9). The diagnostic sensitivity of the LFD (82\%) was similar to that obtained by the reference method of antigen ELISA ( $86 \%$ ), and the diagnostic sensitivity of the LFD was $100 \%$ compared to $99.7 \%$ for the ELISA. This novel technology has several advantages over traditional immunoassays, including low cost, simplic- 
ity and rapid operation (results can be obtained within 15-20 min), and no sophisticated equipment is required.

The clinical resemblance of SVD to FMD highlights the need for its reliable identification and discrimination. In the absence of such identification and discrimination, it is necessary to impose severe restrictions on the movements of pigs for which convincing evidence of being free from the virus or specific antibodies is not available. This poses a significant burden for trade in pigs, and thus the disease, though mild from the clinical point of view, causes severe economic losses for the producers. Improvements in the diagnostic techniques are making the differential diagnosis of the vesicular disease increasingly affordable, feasible and easy, and nowadays, portable devices are capable of a rapid and accurate differentiation of SVDV from FMDV infections on site (22). As these tests become economical and as competent laboratory services become more and more accessible, the constraints originally imposed on SVD because of its similarity to FMD will no longer be justified. This, together with the fact that in recent years SVD has been predominantly asymptomatic (SVD EBrocchi Rome.pdf), makes it necessary to reassess the measures currently in place for the control and diagnosis of SVD. Therefore, by the decision of the OIE, the SVD chapter was removed from the Terrestrial Code in January 2015. However, the SVD chapter in the Diagnostic Manual was retained, and SVD experts, as well as international reference laboratories for SVD (EU RL in Pirbright and OIE RL in Brescia), will continue to operate. Consequently, the European Commission (EC) informed the Pirbright Institute that the EU RL for SVD would not longer receive financial support. Moreover, the EC position is that notification requirements have ceased in January 2015 (www.pirbright.ac.uk).

\section{References}

1. Adams M. J., Lefkowitz E. J., King A. M., Harrach B., Harrison R. L., Knowles N. J., Kropinski A. M., Krupovic M., Kuhn J. H., Mushegian A. R., Nibert M., Sabanadzowic S., Sanfacon H., Siddell S. G., Simmonds P., Varsani A., Zerbini F. M., Gorbalenya A. E., Davison A. J.: Ratification vote on taxonomic proposal to the International Committee on Taxonomy of Viruses. Arch. Virol. 2016, 161, 2921-2949.

2.Bellini S., Alborali L., Zanardi G., Bonazza V., Brocchi E.: Swine vesicular disease in northern Italy: Diffusion through densely populated pigs areas. Rev. Sci. Tech. 2010, 29, 639-648.

3. Bellini S., Santucci U., Zanardi G., Brocchi E., Marabelli R.: Swine vesicular disease surveillance and eradication activities in Italy. Rev. Sci. Tech. 2007, 26, 585-593.

4. Blomstrom A. L., Hakhverdyan M., Reid S. M., Dukes J. P., King D. P., Belak S., Berg M.: A one-step reverse transcriptase loop-mediated isothermal amplification assay for simple and rapid detection of swine vesicular disease virus. J. Virol. Methods 2008, 147, 188-193.

5. Brocchi E., Berlinzani A., Gamba D., De Simone F.: Development of two novel monoclonal antibody-based ELISAs for the detection of antibodies and the identification of swine isotypes against swine vesicular disease virus. J. Virol. Methods 1995, 52, 155-167.

6. Dekker A.: Swine vesicular disease, studies on pathogenesis, diagnosis, and epizootiology: a review. Vet. Q. 2000, 22, 189-192.

7. Fernandez J., Aguero M., Romero R., Sanchez C., Belak S., Arias M., SanchezVizcaino J. M.: Rapid and differential diagnosis of foot-and-mouth disease, swine vesicular disease, and vesicular stomatitis by a new multiplex RT-PCR assay. J. Virol. Methods 2008, 147, 301-311.

8. Fernandez-Pinero J., Pezzoni G., Cano-Gomez C., Fernandez-Pacheco P., Brocchi E., Jimenez-Clavero M. A.: Swine vesicular disease virus, [in:]
Dongyon Liu (ed.): Molecular detection of animal viral pathogens. CRC Press 2016, 89-100

9. Ferris N. P., Nordengrahn A., Hutchings H., Paton D. J., Kristersson T., Merza M.: Development and laboratory evaluation of a lateral flow device for the detection of swine vesicular disease virus in clinical samples. J. Virol. Methods 2010, 163, 477-480.

10. Inoue T., Suzuki T., Sakiguchi K.: The complete nucleotide sequence of swine vesicular disease virus. J. Gen. Virol. 1989, 70, 919-934.

11. Knowles N. J., Wilsden G., Reid S. M., Ferris N. P., King D. P., Paton D. J., Fevereiro M., Brocchi E.: Reappearance of swine vesicular disease virus in Portugal. Vet. Rec. 2007, 161, 71. doi: 10.1136/vr.161.2.71-a.

12. Kubin G.: Appearance of swine vesicular disease in Austria. Wiener Tierarztl. Mschr. 1973, 60, 283-288.

13. Lin F., Kitching R. P.: Swine vesicular disease: an overview. Vet. J. 2000, 160, 192-201.

14. Lomakina N. F., Yu Shustova E., Strizhakova O. M., Felix Drexler J., Lukashev $A$. $N$.: Epizootic of vesicular disease in pigs caused by coxsackievirus B4 in the Soviet Union in 1975. J. Gen. Virol. 2016, 97, 49-52.

15. Murphy F. A., Fauquet C. M., Bishop D. H. L., Ghabrial S. A., Jarvis A. W. Martelli G. P., Mayo M. A., Summers M. D.: Virus taxonomy. Classification and nomenclature of viruses. Sixth report of the International Committee on taxonomy of viruses. Arch. Virol. 1995, suppl. 10, 1-586.

16. Nardelli L., Lodetti G., Gualandi G. L., Burrows R., Goodridge D., Brown F., Cartwirght B.: A foot-and-mouth disease syndrome in pigs caused by an enterovirus. Nature 1968, 219, 1275-1276.

17. Nassuato C., Boender G. J., Eble P. L., Alborali L., Bellini S., Hagenaars T. J.: Spatial transmission of swine vesicular disease in the 2006-2007 epidemic in Lombardy. PloS ONE 8(5): e62878. doi:101371/journal.pone.0062878.

18. Niedbalski $W$.: Application of different diagnostic methods for the detection of SVDV infection in pigs. Bull. Vet. Inst. Pulawy 1999, 43, 11-18.

19. Niedbalski $W$.: Application of real-time reverse transcription polymerase chain reaction for the detection of SVDV. Pol. J. Vet. Sci. 2009, 12, 119-121.

20. Niedbalski W.: Diagnostic value of the isotype-specific ELISA for the detection of antibodies against swine vesicular disease virus (SVDV). Bull. Vet. Inst. Pulawy 2002, 46, 37-44.

21. Niedbalski $W$.: Phylogenetic analysis of Polish isolates of swine vesicular disease virus (SVDV). Bull. Vet. Inst. Pulawy 1999, 43, 139-145.

22. Niedbalski $W$.: Recent progress in the diagnosis of foot-and-mouth disease: rapid field-based assays. Med. Weter. 2016, 72, 339-344.

23. Niedbalski W., Kęsy A., Brocchi E., Borrego B., Malicki K.: Analiza antygenowa polskich izolatów wirusa choroby pęcherzykowej świń. Med. Weter. 1999, 55, 181-184

24. Niedbalski W., Kęsy A., Paprocka G., Fitzner A.: Detection of SVDV RNA amplified by the polymerase chain reaction (PCR). Bull. Vet. Inst. Pulawy 1995, 39, 85-90.

25. Niedbalski W., Kęsy A., Paprocka G., Fitzner A.: Metody immunoenzymatyczne w diagnostyce serologicznej choroby pęcherzykowej świń. Med. Weter. $1998,54,622-628$

26. Nunez J. I., Blanco F., Hernandez T., Gomez-Tejedor C., Martin M. J., Dopazo J., Sobrino F.: A RT-PCR assay for the differential diagnosis of vesicular disease of swine. J. Virol. Methods 1998, 72, 227-235.

27. Reid S. M., Ferris N. P., Hutchings G. H., King D. P., Alexandersen S.: Evaluation of real-time reverse transcription polymerase chain reaction assay for the detection of swine vesicular disease virus. J. Virol. Methods 2004, 116, $169-176$

28. Rueckert R. R.: Picornaviridae and their replication, [in:] Fiels B. N., Knipe D. M. (eds): Virology. Raven Press, Ltd, New York, 1990, p. 707-738.

29. Sandurski A.: Choroba pęcherzykowa świń w fermie przemysłowej. Med. Weter. 1996, 52, 113-115.

30. Senthilkumaran C., Bittner H., Ambagala A., Lung O., Babiuk S., Yang M., Zimmerman J., Gimenez-Lirola L. G., Nfon C.: Use of oral fluids for detection of virus and antibodies in pigs infected with swine vesicular disease virus. Transbound. Emerg. Dis. 2016, doi: 10.1111/tbed.12563.

31. Terpstra C.: Swine vesicular disease in the Netherlands. Tijdschr. Diergeneeskunde 1992, 117, 623-626.

32. Vazquez-Calvo A., Saiz J. C., Sobrino F., Martin-Acebes M. A.: First complete coding sequence of a Spanish isolate of swine vesicular disease virus. Genome Announc. 2016, 4. doi:10.1128/genomeA.01742-15.

33. Zhang G., Haydon D. T., Knowles N. J., McCauley J. W.: Molecular evolution of swine vesicular disease virus. J. Gen. Virol. 1999, 80, 639-651.

34. Zhang G., Wilsden G., Knowles N. J., McCauley J. W.: Complete nucleotide sequence of a coxsackie B5 virus and its relationship to swine vesicular disease virus. J. Gen. Virol. 1993, 74, 845-853.

Corresponding author: dr hab. Wieslaw Niedbalski, assoc. prof., Wodna 7 98-220 Zduńska Wola; e-mail: wieslaw.niedbalski @piwzp.pl 